\title{
A SAÚDE NA DIMENSÃO POLÍTICA DA EDUCAÇÃO: SUBSÍDIOS DA CONCEPCCÃO DE PODER E DIREITO DE HANNAH ARENDT
}

\author{
HEALTH IN THE POLITICAL DIMENSION OF EDUCATION: \\ SUBSIDIES FROM THE CONCEPTION OF POWER \\ AND RIGHT OF HANNAH ARENDT \\ LA SANTÉ DANS LA DIMENSION POLITIQUE DE L'ÉDUCATION : \\ APPORTS DE LA CONCEPTION DE POUVOIR \\ ET DROIT DE HANNAH ARENDT \\ LA SALUD EN LA DIMENSIÓN POLÍTICA DE LA EDUCACIÓN:
SUBSIDIOS DE LA CONCEPCIÓN DE PODER
Y DERECHO DE HANNAH ARENDT
}

Mary Rangel *
Paulo Petry **

RESUMO

Este artigo focaliza a importância da dimensão política da educação para a compreensão da saúde como direito fundamental da vida cidadã e parte essencial da dignidade humana. Enfatizam-se, portanto, os direitos públicos fundamentais, com atenção à saúde, discutindo-se a necessidade de garanti-los e a relevância da conscientização, como processo educativo, em favor da mobilização política da sociedade. Nessa perspectiva, recorre-se à concepção de poder e direito de Hannah Arendt, destacando-se os seus subsídios ao processo de conscientização, necessário ao entendimento da saúde como valor e direito públicos e, portanto, como compromisso político dos governos e uma das condiçôes de sua legitimidade.

Palavras-chave: Educação. Saúde. Política. Teoria de Hannah Arendt. Direitos públicos fundamentais.

* Doutora em Educação pela Universidade Federal do Rio de Janeiro (1990). Professora Titular de Didática da Universidade Federal Fluminense (1994). Professora Titular de Ensino-Aprendizagem da Universidade do Estado do Rio de Janeiro (1995). Pós-Doutora em Psicologia Social pela Pontifícia Universidade Católica de São Paulo (1998). Coordenadora Pedagógica dos Cursos de Graduação da Unilasalle de Niterói, RJ (mrangel@abel.org.br).

** Mestre em Filosofia pela Universidade Gama Filho (2003). Doutor em Ciências Médicas pela Universidade do Estado do Rio de Janeiro (2007), com pesquisa na linha de Informação e Educação em Saúde. Presidente da Associação Brasileira de Educadores Lassalistas - Abel (paulopetry@yahoo.com). 


\section{INTRODUÇÃO}

Não se pode compreender o alcance amplo da educação em favor da saúde, sem base política de conhecimento (PETRY, 2007, p. 42).

A saúde é "tema da vida cidadā", destacado nos termos da Resolução no 2, de 7/4/98, do Conselho Nacional de Educação (BRASIL, MEC, CNE, 1998). Como todos os demais temas da vida cidadã, o estudo das questôes da saúde é recomendado de modo transversal ao currículo. Isso significa que, em todos os componentes curriculares, a saúde deverá ser contemplada.

Contudo, menos por uma questão normativa, e mais pelo significado educacional e, portanto, valorativo e social do conhecimento, é preciso que se observe a dimensão política da educação e seu comprometimento com a saúde.

As dimensões da prática educativa incluem o nível técnico, das competências docentes, o humano, das relações, e o político, da garantia dos direitos públicos e dos deveres do Estado nesse sentido.

Neste artigo, focalizam-se a dimensão política da educação e as considerações à saúde nessa dimensão.

\section{EDUCAÇÃO, SAÚDE E POLÍTICA}

A saúde é um direito social e político, o que equivale a dizer que a saúde é um direito e valor da vida cidadã; essa compreensão da saúde traz, necessariamente, a recorrência à educação conscientizadora e aos fundamentos e conceitos da teoria política.

A teoria política oferece as bases, a sustentação do entendimento dos compromissos da educação com a formação dos sujeitos sociais conscientes dos seus direitos, entre eles o direito à saúde como garantia política e, portanto, dever do Estado.

A relação entre educação, direito, dever e saúde, para ser compreendida em suas premissas e conceitos essenciais, recomenda apoio teórico e conceitual. Esse apoio é necessário para que se possa esclarecer e ampliar a percepção dos vínculos e compromissos dessa relação, auxiliando também a perceber a abrangência dos fatores e implicações da concepção da saúde como objeto da educação, enfatizando a ampliação de conceitos, de visão crítica e de conscientização de direitos.

O que se realça, portanto, são as contribuições dos princípios, processos e práticas educacionais para avanços e ressignificações necessárias à melhor qualidade de vida. Aplicando-se essas reflexões à saúde, observa-se que o seu conceito supera, hoje, os limites do enfoque orgânico, para alcançar dimensões mais amplas e reais de suas implicações e fatores políticos, necessários às decisões e ações que possam garantir a prevenção à doença e a superação de problemas que prejudicam a qualidade (orgânica e social) de vida sadia.

Reafirma-se, então, que a saúde envolve condiçôes de vida de qualidade, nas quais sejam assegurados os direitos de cidadania, e que a educação é comprometida com essa 
visão e consciência. Nesse sentido, saúde é objeto essencial das decisões políticas em favor da coletividade (da polis, do povo), cujos interesses e direitos de vida cidadã constituem o núcleo da ciência política e parte essencial da dimensão política da prática educativa.

A política legítima, correta e conceitualmente afinada com o significado de Ciência Politica, é a que se exerce de modo a serem garantidas as condiçôes de infra-estrutura, saneamento, habitação, educação, trabalho, atendimento médico e odontológico preventivo, vacina, informações, orientações e esclarecimentos ao público, enquanto condições necessárias à saúde. Todos esses fatores representam, portanto, direitos públicos fundamentais, conhecê-los e reivindicá-los constituem requisitos de conscientização social desses direitos, processo que caracteriza a dimensão política da educação.

Entretanto, em pesquisas como as de Semeraro (2004), constata-se a dificuldade em objetivar, no discurso e na prática, a dimensão política das práticas sociais, entre elas as práticas educativas. Reafirma-se, então, que toda prática social é fundamentada, o que significa dizer que encontra sentido e perspectivas na sustentação teórica de princípios e conceitos, sendo importante que se considere, nas ações e reivindicações da sociedade, os referenciais teóricos que possam embasá-las; um desses referenciais encontra-se, sem dúvida, pela consistência e atualidade de seus pressupostos conceituais e paradigmáticos, na teoria política de Hannah Arendt (1972, 1973a, 1973b, 1978, 1987a, 1987b).

Assim, não se pode prescindir, nos fundamentos e processos da prática educativa, de teorias que possam esclarecer questôes relativas a concepçōes e princípios de direitos políticos, necessários e significativos para a conscientização social sobre o direito à saúde. E o realce da dimensão política do ato educativo, com atenção à saúde e outros direitos, encontra, nos conceitos de Hannah Arendt, subsídios relevantes e necessários, especialmente em tempos de apelos às garantias dos direitos públicos fundamentais, sem perder de vista, também, o enfrentamento da violência, que não é só a que ameaça a vida pelo uso de armas, mas também a que ameaça a vida pela ausência ou omissão política frente às condições, sociais e cidadãs, de vida com dignidade.

Assim, é preciso, sem dúvida, reafirmar a importância de que se amplie, na visão e ação dos educadores, o conceito de saúde, no intuito de que seja ensinado e aprendido na perspectiva de ir além dos aspectos orgânicos, no interesse de que se possa alcançar o sentido da saúde como direito público.

Os direitos públicos têm sido, freqüentemente, desconsiderados. No caso brasileiro, por exemplo, no campo da saúde, encontram-se dados por meio dos quais se observam questões sérias, que ameaçam, inclusive, a sobrevivência de crianças. O Fundo das Nações Unidas para a Infância (Unicef) aponta 27 milhões de crianças no Brasil vivendo abaixo da linha de pobreza e um índice de 35 mortes a cada mil nascimentos.

A pobreza, os conflitos armados e a Aids são, no início do século 21, as maiores ameaças às crianças e aos adolescentes no mundo, de acordo com o relatório anual do Fundo das Naçōes Unidas para a Infância. No Brasil, dos três problemas, o que mais preocupa o órgão da ONU é a pobreza (JB ON LINE, 2004, p. 1).

Problemas dessa natureza são, essencialmente, políticos e requerem a participação indispensável da prática educativa e seus princípios e processos de formação e desenvolvimento 
humano. E é, principalmente, a mobilização da sociedade civil, a partir da sua conscientização política, que constitui o testemunho e a motivação da obra de Hannah Arendt: vida e obra que, embora não tivessem, essencialmente, como objeto, a educação, trazem subsídios indispensáveis à compreensão da saúde como direito e oferecem, pelos seus princípios e conceitos, fundamentos significativos à dimensão política da educação.

\section{FUNDAMENTOS TEÓRICOS DA DIMENSÃO POLÍTICA DA EDUCAÇÃO EM HANNAH ARENDT}

Para chegar aos conceitos de poder, política e direito, que podem fundamentar os educadores na sua ação em favor da compreensão político-social da saúde e suas garantias, é interessante rever alguns elementos da história e da produção de Hannah Arendt, para entendê-la melhor em sua luta pela condição humana de ser e viver com dignidade (ARENDT, 1987a). Assim, a revisão que se faz da teoria arendtiana contempla elementos de sua vida e obra e da concepção de poder e direito, considerando-os relevantes como subsídios aos fundamentos teóricos da dimensão política da educação em favor da consciência do direito à saúde.

Hannah Arendt - Hannover, 1906 e Estados Unidos, 1975 - foi uma expressiva filósofa política. Forçada a deixar a Alemanha, após a instauração do regime nazista, vive na França até 1941, quando se refugia nos Estados Unidos, escapando, desse modo, à ocupação da França pelos alemães.

No âmbito de sua produção, Arendt reflete sobre fatores que geram a violência, destacando, nesses fatores, as circunstâncias sub-humanas de vida e a violência que a falta de condições de dignidade humana representa. Assim, a autora propõe a reivindicação dos direitos públicos fundamentais, realçando a importância da mobilização social, em prol desses direitos.

Pela mesma atenção aos direitos públicos e à mobilização social em prol desses direitos, a teoria arendtiana procura acentuar a relevância de leis e de instituições legitimadas pela opinião pública, ao mesmo tempo em que enfatiza a garantia do espaço político, enquanto espaço social da palavra e da ação, em favor do respeito à humanidade.

Assim, Hannah Arendt constrói, em sua formulação teórica, uma argumentação coerente e consistente sobre a importância da dimensão política em todos os campos de realizações humanas, oferecendo conceitos e princípios que a fundamentam, com expressivo significado e interesse social, especialmente em "tempos sombrios" (ARENDT, 1987b), que tensionam a sociedade. Nesses tempos, recorre-se mais fortemente aos conceitos e valores das garantias políticas aos direitos sociais.

Desse modo, confirma-se o entendimento de que a concepção arendtiana de poder e direito oferece subsídios expressivos aos fundamentos políticos da educação e suas contribuições e compromissos com a compreensão, ampla e consciente, da saúde.

Ainda, na análise sobre a natureza do poder, Hannah Arendt (1978, p. 72) questiona as perspectivas de dominação e violência impostas por regimes totalitários, ou, então, em 
outras circunstâncias, disseminadas socialmente, pela ausência de autoridade legitimamente constituída e pela omissão política, que repercute na ausência de limites de conduta, na impunidade, na falta de segurança pública e na desconsideração à dignidade humana. A confiança, a paz e os direitos da vida cidadã ficam, portanto, ameaçados, e um dos fatores dessa ameaça é a perda do poder e da autoridade por ele exercida. Essa perda é devida a "uma constante crise de autoridade, sempre crescente e cada vez mais profunda, que acompanhou o desenvolvimento do mundo moderno em nosso século" (ARENDT, 1972, p. 128).

Uma outra questão significativa do conceito de poder legítimo em Hannah Arendt é a importância do acordo e da ação comuns, alcançados pela comunicação entre as pessoas. Essa comunicação é essencial para que possa haver a mobilização da sociedade em favor dos seus direitos, o que representa uma prática significativa, realizada no espaço político, lembrando-se que esse espaço define-se como um ambiente público, aberto à palavra e à ação. Esse princípio da teoria arendtiana pode oferecer à educação, como processo conscientizador, fundamentos teóricos relevantes.

Politicamente, a autoridade só pode adquirir caráter educacional se se admite, com os romanos, que sob todas as circunstâncias os antepassados representam o exemplo de grandeza para cada geração subseqüente, que eles são os maiores, por definição. Sempre que o modelo de educação, através da autoridade, sem essa convicção fundamental, foi sobreposto ao reino da política (e isso sucedeu não poucas vezes, sendo ainda um esteio da argumentação conservadora), serviu basicamente para obscurecer pretensōes reais ou ambicionadas ao poder, e fingiu querer educar quando na realidade tinha em mente dominar (ARENDT, 1972, p. 161).

Chega-se, com essas considerações, à análise da natureza comunicativa do poder, especialmente enfatizada na leitura e discussão do pensamento arendtiano por Habermas (1980) e Celso Lafer (1979).

Observa-se, assim, que a comunicação que gera o acordo e possibilita a ação comum, o agir em comum em prol da garantia política de condiçôes de vida cidadã - vida plena, vida com dignidade, vida saudável - envolve várias questões, entre as quais se destaca e reafirma a importância da autoridade, que é incompatível com a coerção e a persuasão.

Visto que a autoridade sempre exige obediência, ela é comumente confundida como alguma forma de poder ou violência. Contudo, a autoridade exclui a utilização de meios externos de coerção; onde a força é usada, a autoridade em si mesmo fracassou. A autoridade, por outro lado, é incompatível com a persuasão, a qual pressupõe igualdade e opera mediante um processo de argumentação. Onde se utilizam argumentos, a autoridade é colocada em suspenso. Contra a ordem igualitária da persuasão ergue-se a ordem autoritária, que é sempre hierárquica. Se a autoridade deve ser definida de alguma forma, deve sê-lo, então, tanto em contraposição à coerção pela força, como à persuasão através de argumentação (ARENDT, 1972, p. 129).

Trazendo, então, esses princípios para os estudos e pesquisas no campo da dimensão política da educação e seus compromissos com a saúde, pode-se compreender que o fortalecimento das instituiçóes e o respeito às leis possam ser alguns dos pré-requisitos a que se preservem e pratiquem as condições de vida cidadã, entre elas as condições de segurança, paz e vida saudável. 
A linguagem, a palavra, a comunicação, o "agir conjunto" são questôes importantes na construção da legitimidade do poder, que é conferido pelo apoio e confiança da sociedade: apoio e confiança gerados pelas garantias de vida com dignidade; e não há poder legítimo sem compromisso com essas garantias.

Por isso, ao discutir a legitimidade do poder, Arendt (1972) lembra a compreensão de poder e direito gregos, cuja essência não repousava em relações de dominação, omissão ou indiferença, mas sim de apoio às necessidades e apelos sociais. O exercício do poder legítimo rejeita o domínio do homem sobre o homem, rejeita o sistema de privilégios, rejeita toda forma de violência, omissão ou desrespeito às condiçôes que prejudicam a qualidade de vida e, portanto, de humanidade.

O poder legítimo é o que assegura a obediência a leis apoiadas pelos cidadãos e formuladas no seu interesse. Torna-se, portanto, relevante o "agir conjunto" da sociedade pelo cumprimento das leis que por ela e para ela são elaboradas. Nessa perspectiva arendtiana, podem-se encontrar, mais uma vez, princípios que fundamentam a conscientização e seu entendimento como processo inerente à dimensão política da educação.

Reafirma-se, desse modo, consolidando o mesmo princípio político da mobilização social, que a ação e a comunicação que geram o acordo comum sobre os direitos fundamentais do povo são condiçôes de apoio às leis e de legitimação do poder, pelo reconhecimento da autoridade dos governantes. A quebra desses direitos resulta na desqualificação dos governos e de seus políticos pela sociedade.

Volta-se, então, ao princípio de que o poder legítimo decorre da opinião pública, de onde se conclui que o desrespeito à vida humana e a desconsideração, o desrespeito, ou omissão frente às garantias dos seus direitos fundamentais constituem as formas menos qualificadas de governo; sua natureza e suas manifestações de "poder" são ilegítimas.

Reflexões dessa natureza, aplicadas à dimensão política da educação e sua prática em favor da compreensão da saúde como direito fundamental, ampliam o entendimento do compromisso do Estado em garantir as suas condiçōes sociais básicas, assim como a importância de que a sociedade se mobilize, pela palavra e pela ação coletiva, nesse sentido.

As reflexões sobre a ausência da política legítima, a qual resulta na ausência das condições humanas de qualidade de vida e de sobrevivência, são relevantes para se perceber que a saúde é uma dessas condições e que compreendê-la como um direito é um princípio indispensável ao exercício pleno da cidadania; e o exercício pleno da cidadania requer o pensamento crítico-social, numa perspectiva dialética e, portanto, requer e convoca a prática educativa, na dimensão política de seu processo de conscientização.

Renova-se, portanto, mais uma vez, nesse princípio, a importância de que, nesse processo educativo conscientizador, compreenda-se que os espaços do mundo político definem-se como espaços públicos da palavra e da ação, exercidos em favor da cidadania e da vida com dignidade: "a vida ativa", enfatizada por Arendt (1987a, p. 37), que possibilita o pensamento e a palavra geradora da comunicação e ação coletiva.

Nesse sentido, volta-se a destacar que a ação coletiva, a participação política autêntica do povo, da sociedade civil, são, realmente, grandes preocupações de Hannah Arendt (1972). Preocupações dessa natureza fundamentam a perspectiva política das práticas 
sociais de modo geral, e da prática educativa, de modo especial, pelo valor da formação da consciência política, necessária à compreensão e reivindicação de direitos.

Sublinha-se e consolida-se, portanto, o princípio de que a ação política da sociedade, que se realiza nos espaços públicos da palavra e da ação, acrescenta realce, relevância, confiabilidade e, portanto, autoridade às instituições e às leis. Esse aspecto traz, novamente, a questão de que é o apoio da comunidade política que confere autoridade ao poder comprometido com as garantias dos direitos públicos fundamentais.

Vale, então, novamente lembrar que o mundo moderno tem passado por uma crescente crise de autoridade, que se manifesta desde o início do século XX. Em Crises da República, Hannah Arendt (1973a, p. 64) apresenta uma observação muito significativa a esse respeito, quando diz que, no mundo moderno, houve o "desprezo pela autoridade" e "as leis parecem ter perdido o poder"; por isso, a vida humana tem sido, crescentemente, ameaçada.

Do ponto de vista histórico, a perda da autoridade foi o segmento final e decisivo do mesmo processo que extinguiu a religião e a tradição. Autoridade, tradição e religião relacionam-se a valores do passado, à preservação da "fundação" (construção/constituiçãa) das comunidades políticas, do respeito às leis e instituições e, portanto, do respeito ao povo $e$ aos seus direitos.

Nessa mesma perspectiva de análise, a autora procura realçar os prejuízos à segurança e à paz decorrentes da ruptura com o passado, com a tradição, com o respeito às leis e o respeito à autoridade, com a consideração a limites éticos de conduta. Essa ruptura se representa no título atribuído a livro Entre o Passado e o Futuro (ARENDT, 1972).

Reafirma-se, desse modo, a concepção política da violência, essencial na teoria arendtiana. A violência é "instrumento" (meio, estratégia) de dominação usada por governos totalitários, para impor um poder deteriorado pelo descrédito público. Contudo, a violência não é capaz de criar ou sustentar o poder. A ausência de limites sociais promove a disseminação e naturalização da violência, permitida pela impunidade ou omissão dos governos. E a violência tem diversas formas e expressōes, mas um efeito comum: a deterioração da qualidade de vida.

Com esses conceitos políticos - de poder, autoridade, violência, falta de respeito aos direitos públicos fundamentais -, Hannah Arendt desenvolve o seu pensamento, cujos princípios e conceitos, refletidos e reafirmados, em várias abordagens deste texto, podem trazer expressivas contribuições à dimensão política da educação, comprometida com a formação de sujeitos conscientes do valor da participação da sociedade na vida política, de forma democrática, plural, comunicativa, livre e saudável.

Assim, nessa revisão de conceitos e princípios, observa-se que a leitura de Arendt inspira e traz motivaçôes e premissas significativas à visão do real significado de política e seus compromissos com os direitos públicos, essenciais à "vida ativa". Essas motivaçôes e esses conceitos trazem elos significativos entre a educação, em sua dimensão política, e o entendimento da saúde como direito, com o qual a educação se compromete, destacando-se, nesse sentido, o seu papel conscientizador. 


\section{CONSIDERAÇÃO FINAL}

Num momento em que se enfatizam os direitos de cidadania e em que se questiona a falta de condiçôes de preservação e garantias desses direitos, observando-se a acentuação da pobreza e suas conseqüências na saúde (e aqui se pode considerar não só as condiçõos orgânicas, como também as condiçôes de saúde social, ou seja, as condiçốes humanas de uma sociedade saudável), a teoria política tem contribuiçôes expressivas a oferecer à dimensão política da educação em sua finalidade e processos de conscientização.

Sabe-se da diversidade de enfoques e conceitos em teoria política. Contudo, sem dúvida, nessa variedade de conceitos e perspectivas, o pensamento de Hannah Arendt se destaca, de modo especial, pelos termos, pela projeção, pela expressividade, atualidade e relevância de suas consideraçõos e argumentos.

O conhecimento, a informação, a formação e conscientização política são direitos da sociedade, em todas as áreas de realização humana, destacando-se, de modo particular, a área da educação, pelo seu comprometimento com as condições essenciais de vida com dignidade: vida ativa, vida saudável.

É oportuno, então, lembrar, como elementos que se acrescentam às análises deste texto, que os princípios gerais do direito - legalidade, igualdade, publicidade, realidade, sindicalidade e responsabilidade - constituem a base da cidadania; a educação e a saúde constituem fatores essenciais à "condição humana" (ARENDT, 1987a) de vida cidadã.

A legalidade determina o respeito às leis. A igualdade refere-se ao princípio da isonomia. A publicidade determina o direito do povo à informação, ao conhecimento sobre suas garantias políticas. O princípio da realidade referenda o direito público à verdade, à transparência, sem distorçôes ou camuflagens. A sindicalidade fundamenta o direito à sindicância e ao controle dos atos públicos. Pelo princípio da responsabilidade, os sujeitos sociais assumem, como direito e dever, o compromisso e as conseqüências inerentes às suas ações e decisões.

Considerando, ainda, os direitos públicos como direitos de cidadania, observados em Moreira Neto (1998), mais uma vez se constata que não se pode compreender o alcance amplo da educação em favor da saúde, sem uma base política de conhecimento, realçando-se, nesse interesse, a importância de que os educadores conheçam e incorporem ao processo de conscientização algumas das noções básicas sobre direitos fundamentais e sobre princípios da teoria política, a exemplo da teoria arendtiana.

Sublinha-se, então, o princípio de que as condições de vida saudável definem-se e realizam-se politicamente na e para a sociedade. E as definiçõos político-sociais da saúde constituem princípios e parâmetros das convicções e ações dos governos que assumem o poder legítimo que lhes é conferido pelo povo, pela polis.

A ênfase atual nesses princípios políticos e nos compromissos que lhes são inerentes relaciona-se à ênfase no comprometimento do Estado com a ética, o direito, a cidadania: três elementos da formação humana e social mutuamente recorrentes na prática da dimensão política da educação. 
Ética e cidadania, núcleos da vida política, associam-se a direitos e deveres, para que sejam garantidas as condições de saúde necessárias à vida com dignidade, segurança e paz: apelos e necessidades prementes de "tempos sombrios" de desconsideração aos direitos públicos fundamentais. Por isso, realça-se, mais uma vez, a importância dos conceitos arendtianos, no interesse da conscientização da sociedade civil, para que a cidadania possa se exercer no espaço público da palavra e da ação, que caracteriza o mundo político: um mundo no qual os sujeitos sociais vão exercer seu papel como construtores desse espaço, praticando e reivindicando, de modo consciente e fundamentado, os seus direitos.

Os princípios da legitimidade do poder e dos compromissos da política com a dignidade que caracteriza a condição humana (ARENDT, 1987a) podem auxiliar, de modo significativo, os educadores na perspectiva da compreensão da saúde como direito e da consciência da importância da palavra, da ação, da mobilização social no sentido de reivindicá-lo.

\section{Referências}

ARENDT, Hannah. A condição humana. Rio de Janeiro: Forense - Universitária, 1987a.

. Crises da república. São Paulo: Perspectiva, 1973a.

. Da violência. Brasília: Edunb, 1973b.

. Entre o passado e o futuro. São Paulo: Perspectiva, 1972.

. Homens em tempos sombrios. São Paulo: Companhia das Letras, $1987 \mathrm{~b}$.

. O sistema totalitário. Lisboa: Publicações Dom Quixote, 1978.

BRASIL. MEC. CNE. Resolução 2, de 7 de abril de 1998. Impresso.

HABERMAS, Jürgen. O conceito de poder em Hannah Arendt. In: FREITAG, Bárbara; ROUANET, Sergio Paulo (Orgs.); FERNANDES, Florestan (Coord.). Habermas. São Paulo: Ática, 1980, p. 100-118.

JB ON LINE. Infância ameaçada. Disponível em: <http://jbonline.terra.com.br/jb/ papel/brasil/2004/12/09/jorba20041209003.html>. Acesso em: 10 dez. 2004.

LAFER, Celso. Hannah Arendt: pensamento, persuasão e poder. Rio de Janeiro: Paz e Terra, 1979. MOREIRA NETO, Diogo de Figueiredo. Curso de direito administrativo. Rio de Janeiro: Forense, 1998.

PETRY, Paulo. A dimensão politica da informação e educação em saúde. 2007. 2 v. $290 \mathrm{f}$. Tese (doutorado), Faculdade de Ciências Médicas, Universidade do Estado do Rio de Janeiro, RJ.

SEMERARO, Giovanni (Org.). Filosofia e politica. Aparecida/SP: Idéias \& Letras, 2004. 


\section{Health in the political dimension of education: subsidies from the conception of power and right of Hannah Arendt} Abstract

This article focuses on the importance of the political dimension of education for the comprehension of health as a fundamental right of citizen life and as an essential part of human dignity. We emphasize, therefore, the fundamental public rights, with attention to health, discussing the need to guarantee them and the relevance of awareness, as an educational process, in favor of the political mobilization of society. In this perspective, we turn to the conception of power and right of Hannah Arendt, underlining the subsidies to the process of awareness, needed for the understanding of health as a value and a public right and, therefore, as a political commitment of governments and one of the conditions to their legitimacy.

Keywords: Education. Health. Politics. The Theory of Hannah Arendt. Basic public rights.

\section{La santé dans la dimension politique de l'éducation : apports de la conception de pouvoir et droit de Hannah Arendt}

Résumé

Cet article est centré sur l'importance de la dimension politique de l'éducation pour la compréhension de la santé comme droit fondamental de la vie citoyenne et partie essentielle de la dignité humaine. L'on met l'emphase sur les droits publics fondamentaux, avec attention sur la santé, tout en discutant le besoin de les garantir et la relevance de la conscientisation, comme processus éducatif, en faveur de la mobilisation politique de la société. Dans cette perspective, on a recourt à la conception du pouvoir et droit de Hannah Arendt, soulignant les subsides du processus de conscientisation, nécessaire à la compréhension de la santé comme valeur et droit publics et, alors, comme compromis politique des gouvernements et une des conditions de leur légitimité.

Mots clefs : Education. Santé. Politique. Théorie de Hannah Arendt. Droits publics fondamentaux.

\section{La salud en la dimensión política de la educación: subsidios de la concepción de poder y derecho de Hannah Arendt \\ Resumen}

Este artículo enfoca la importancia de la dimensión política de la educación para la comprensión de la salud como derecho fundamental de la vida ciudadana y parte esencial de la dignidad humana. Se enfatiza, por lo tanto, los derechos públicos fundamentales, con atención a la salud, discutiéndose la necesidad de garantizarlos y la relevancia de la conscientización, como proceso educativo, a favor de la mobilización politica de la sociedad. En esa perspectiva, se recurre a la concepción de poder y derecho de Hannah Arendt, destacándose sus subsidios al proceso de conscientización, necesario al entendimiento de la salud como valor y derecho públicos y, por lo tanto, como compromiso político de los gobiernos y una de las condiciones de su legitimidad.

Palabras-clave: Educación. Salud. Politica. Teoría de Hannah Arendt. Derechos públicos fundamentales.

$I^{\text {a }}$ versão recebida em: 23.04 .2007

$2^{\mathbf{a}}$ versão aceita em: 14.03.2008 